\section{Microscopical Evaluation of Glass Delamina- tion in Pharmaceutical Vials: A Look at Three Different Vial Manufacturers}

\author{
Kristie Diebold \\ McCrone Associates \\ kdiebold@mccrone.com
}

Delamination is defined as separation into constituent thin layers (lamellae). Glass delamination, which can have several causes, could then be defined as a separation of surface glass, as from a vial, into thin layers resulting in a flaky appearance. Pitting could be related to, or even be the initial stages of glass delamination; data will be provided that supports a relationship. The presence of glass delamination is a serious concern to the pharmaceutical industry, not only because suspended glass flakes in any pharmaceutical product poses an obvious health hazard, but because of regulatory quality control standards, and medical profession requirements.

There are, of course, many ways of addressing the problem of glass delamination in pharmaceutical vials, including looking into the relationship of chemical nature of vial contents to degree of delamination and conditions of vial manufacture. Specialized lighting and imaging methods are other research approaches. The results from the present microscopical study, although confined to the vials of only three different manufacturers, indicate support for the theory that pitting may be the precursor or early indicator of full-scale glass delamination.

As already suggested, glass delamination in pharmaceutical vials can occur during manufacturing of the vial, e.g. fusion at the neck or base, where delamination and/or pitting are frequently found; or by adverse reaction to the vial contents, e.g. etching due to an acidic or basic solution, or one with a high sodium/salt content. Solution-filled vials often show delamination at the fill line. The fill line is the top most point in the vial where the drug solution reaches. For analytical purposes, therefore, such suspect vials should be left filled for submission to the laboratory. From the standpoint of the microscopist this point must be emphasized. In the past we have been obliged to speculate a fill-line delamination in an empty vial based on previous experience with fill-line delamination problems. Filled vials are vastly preferred by analytical microscopists because such fill lines can be recorded, and, most importantly, the contents can be filtered under cleanroom conditions, in order to concentrate and study the glass delamination. Figure 1, for example, is a reflected-light photograph of delaminated glass recovered on a polycarbonate membrane filter; the brown colored flakes seen in the photo are thinner than those showing interference colors.

McCrone Associates received a project from a pharmaceutical company that requested comparison of the amount of glass delamination from three different glass vial manufacturers. The vials were received empty, but had previously contained the product except for one reference vial. The product was described as strongly basic. All vials were subjected to the same temperatures and time studies documented and provided by the client. All photomicrographs were taken in reflected light. For confidentiality purposes, the

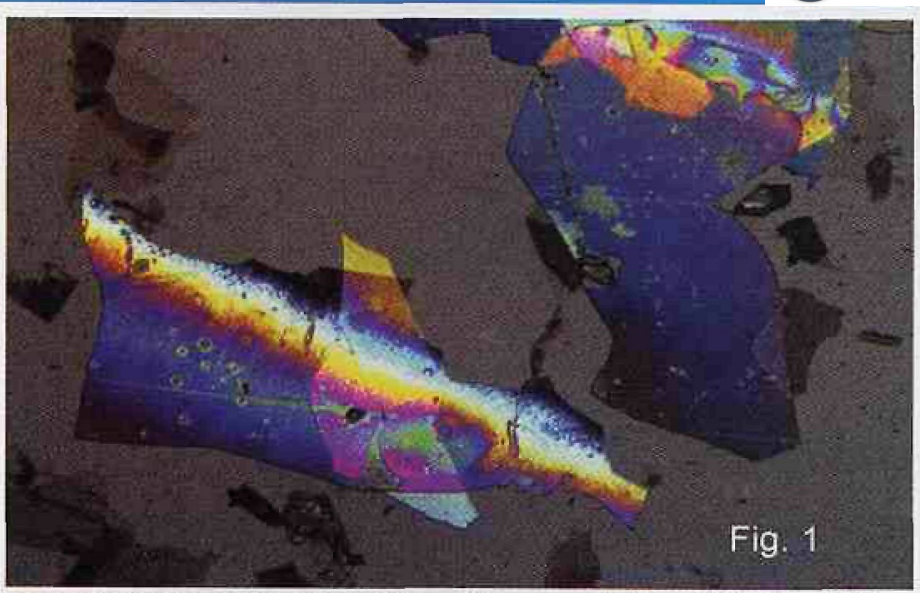

manufacturers will be referred to as Company A, B, and C. In addition to determining the amount of glass delamination, further analysis was requested for Company $B$ only, due to an unusual vertical-striation appearance. The first set of three vials represented all three manufacturers and was identified as having been kept at $55^{\circ} \mathrm{C}$ for a two week period. The second set of vials represented Company $\mathrm{B}$ and was identified as having been kept at $40^{\circ} \mathrm{C}, 30^{\circ} \mathrm{C}, 25^{\circ} \mathrm{C}$, and $4^{\circ} \mathrm{C}$ respectively for a four week period. The third set was Company $\mathrm{B}$ only, and identified as having been kept at $40^{\circ} \mathrm{C}, 30^{\circ} \mathrm{C}, 25^{\circ} \mathrm{C}$, and $4^{\circ} \mathrm{C}$ respectively for an eight week period. In addition to these client-supplied vials, we requested for our own research purposes vials from Companies $\mathrm{A}$ and $\mathrm{C}$ that had been kept at $40^{\circ} \mathrm{C}, 30^{\circ} \mathrm{C}, 25^{\circ} \mathrm{C}, 4^{\circ} \mathrm{C}$ for a four week period.

The findings from the study of the first set revealed pitting in vials from all three companies (pitting can be seen in the flakes in Figure 1). Company A's pitting was at the base of the vial; Company C's was at the base, and fine pitting was found at the neck of the vial; Company $B$ 's pitting was found throughout the vial. Delamination was definitely present in the vials from Company $A$ and $C$; both delamination bands
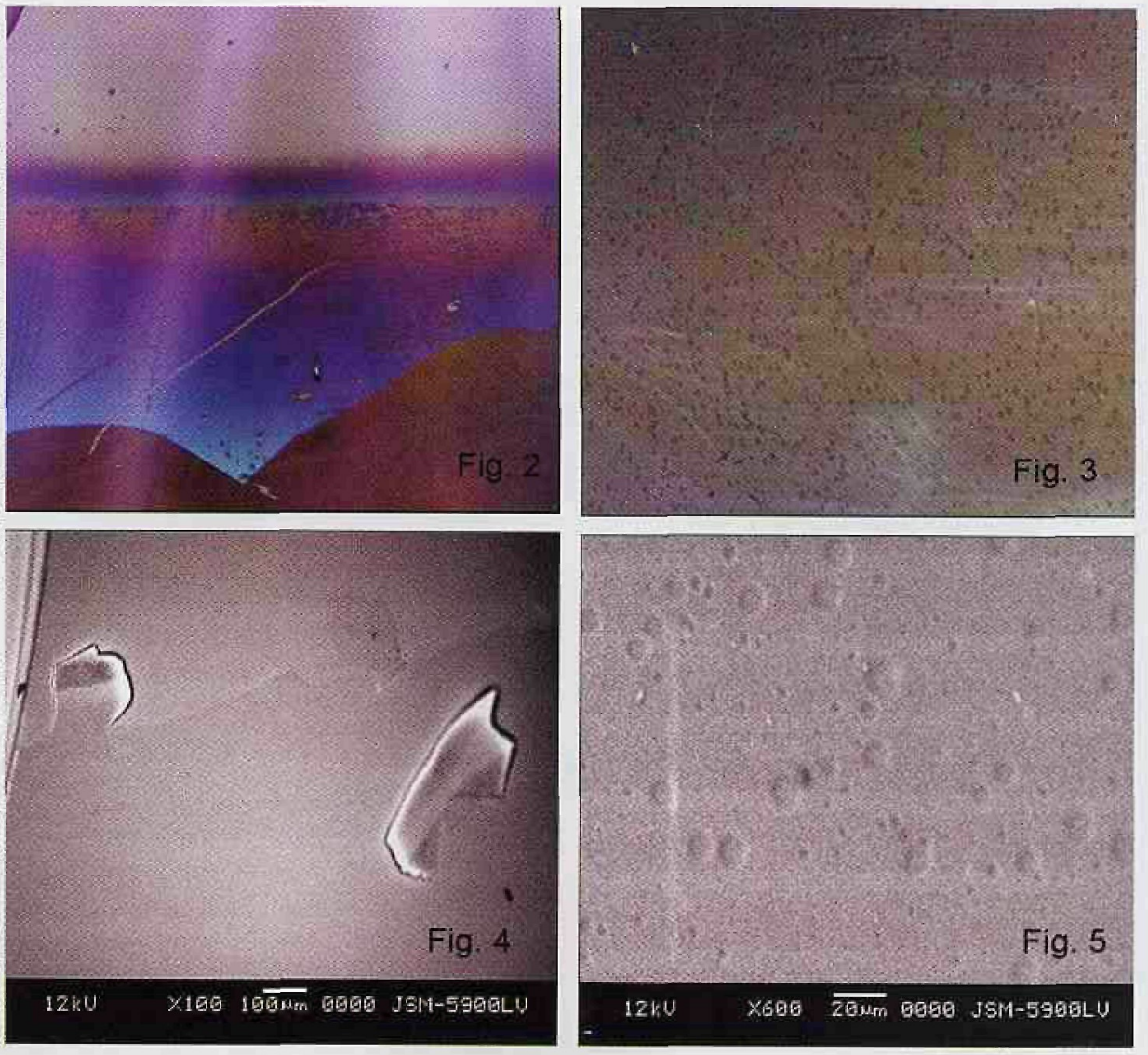


\section{RevolutionTEM ${ }^{\text {TM }}$ Revolution EDX RevolutionSEM}

One software application for TEM \& SEM

- $x$-ray spectrum acquisition \& analysis

- x-ray mapping

- digital imaging

\section{EDX Systems}

- light-element $x$-ray detection

- digital pulse processing

\section{CCD Camera Systems}

- 1.6 to 16 Megapixels

- publication-quality digital images

- flexibility without complexity

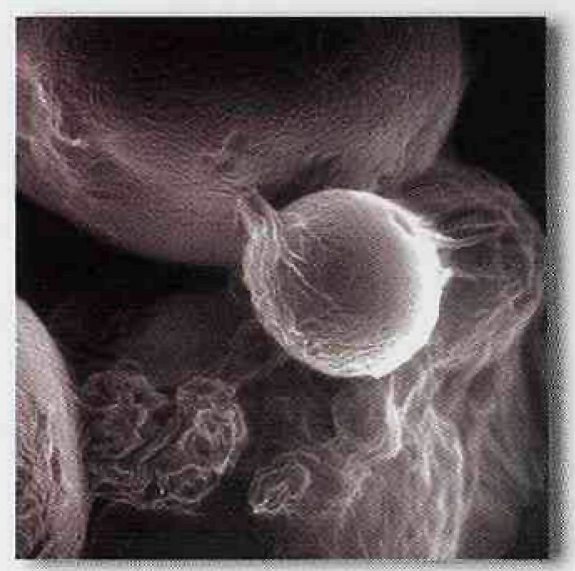

Unparalleled SEM beam-positioning accuracy

\section{EDX and DIGITAL IMAGING}

Systems and Upgrades for TEMs, SEMs, STEMs, and EMPAs. Innovation in desktop EDX and Imaging solutions since 1990 .

4 pi Analysis, Inc. www.4pi.com • info@4pi.com 919-489-1757 
were common to what was believed to have been the fill line. Company C's delamination is closer to the base of the vial, because the vial was larger than $A$ and $B$; it could be assumed the vial is filled with the same amount of solution. Company $B$ had two horizontal rings of defects that were not positively identified as delamination. Something not commonly seen was vertical striations down the entire vial, and brown residue within the striations. Analysis will provide results of these findings.
Figure 6 shows the strange vertical striations and the brown residue within the striations from Company B. Figure 7 shows that the "defects" of Company B's vials are very similar to the delamination bands of the other company's vials. They look slightly different, and were at the very neck region of the vial, possibly the fill line. No IR spectrum of this delamination was obtained because a representative sample could not be removed.Company C's vial had larger pitting at the base, similar to Figure 3 , whereas at the neck, pitting was finer, which is shown in Figure 8. SEM images were also taken to show tapering of and enlargement of the pitting (Figures 9 and 10). Delamination is shown in Figure 11. The whitish line shown by SEM in Figure 12 provides detail of the delamination and the flakes starting to slough off. Again, an IR spectrum was obtained to show a $\sim 1100 \mathrm{~cm}^{-1}$ band, which is a characteristic of silica; again, suggesting glass. The second group of vials examined included three sets of four vials, each having been kept at $40^{\circ} \mathrm{C}, 30^{\circ} \mathrm{C}, 25^{\circ} \mathrm{C}$, and $4^{\circ} \mathrm{C}$ respectively for a four-week period. Company A's vials resulted
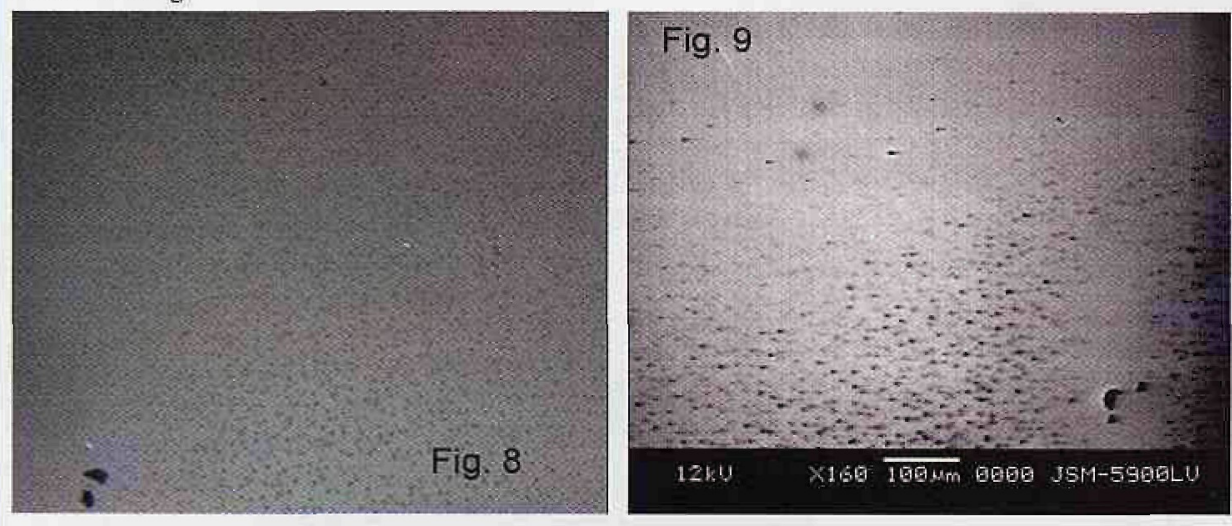

Fig. 10

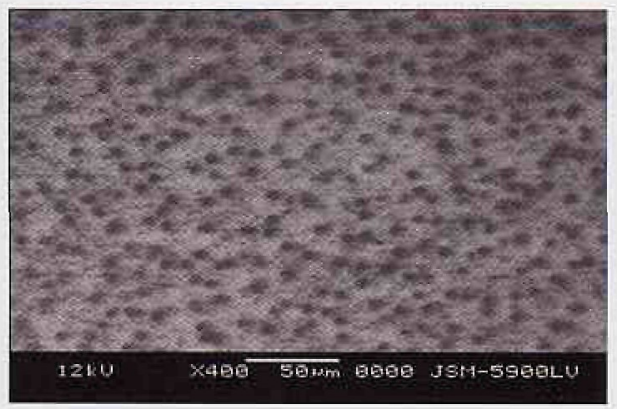

Figures 2 and 3 show delamination and pitting for Company A's vials. There is a dark pink/brown residue below the delamination band; and there is pitting at the base of the vial that could be a thinner area of delamination. Scanning electron microscope (SEM) images show delamination (Figure 4) and pitting (Figure 5); a flake and a piece flaking off can be seen in Figure 4: pitting can be visualized going beneath the surface in Figure 5. The pink/brown residue seen in company A's vials was isolated for infrared spectrometry (IR), along with delamination flakes, to see if there was a similarity between them so as to be able to conclude whether or not the residue could be delamination. $\mathrm{X}$-ray photoemission spectrometry (XPS) was also used to compare the delamination and residue. All IR spectra show the broad band at $\sim 1100 \mathrm{~cm}^{-1}$ which is characteristic of silica, suggesting glass. We can conclude from this information that the delamination and residue are similar.

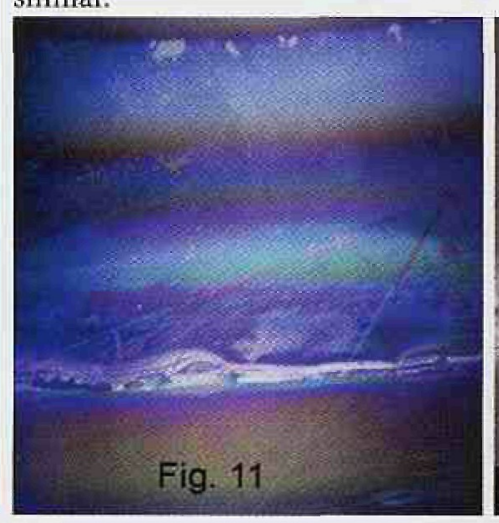

in pitting at the base of the vial at all temperatures and finer pitting in the neck area, as seen in Figure 8. Delamination was found $\sim 1 / 2$ inch from the top of the vial; this area is common to the fill line. The pinkish residue is seen, but only for the $40^{\circ} \mathrm{C}$ sample. Again, this residue is believed to be thin delamination.

The vials of Company B contained pitting at all temperatures except $4^{\circ} \mathrm{C}$. There was no delamination found. The strange vertical striations were visible at all temperatures along with the residue/ discoloration between the striations, similar to the first study. A reference vial that had no contact with solution was sent in that only showed very faint striations.

The vials of Company $\mathrm{C}$ displayed pitting at every temperature but only at the base of the vial. At $4^{\circ} \mathrm{C}$ only pitting was found. Delamination was common $\sim 3 / 4$ inch from the bottom at $40^{\circ}, 30^{\circ}$, and $25^{\circ} \mathrm{C}$. 


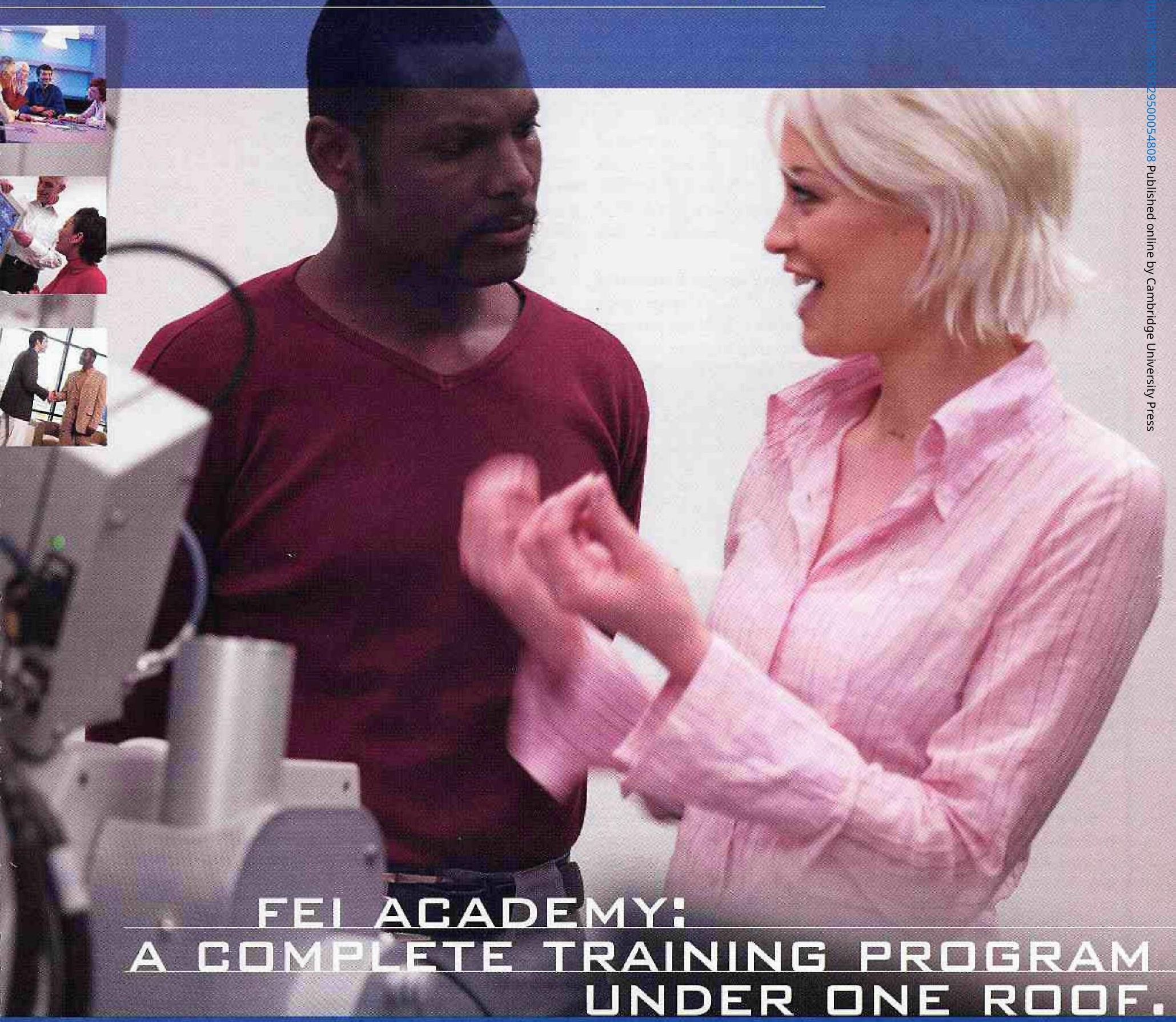

Enabling your access to smart data, and to ensure that you get started fast, FEI Academy offers dedicated TecnaiTM $\mathrm{G}^{2}$ training and applications programs for novice operators through to experienced microscopists. The FEl Academy aims to share and transfer operational skills, and to show the versatility of various electron microscopy techniques. Above all, it strives to show you how to reach your best result for different applications.

WELEDME TU FEI. INVESTMENT IN PEDPLE AND THE FUTURE,

FEI COMPANY

TOOLS FOR NANOTECH 


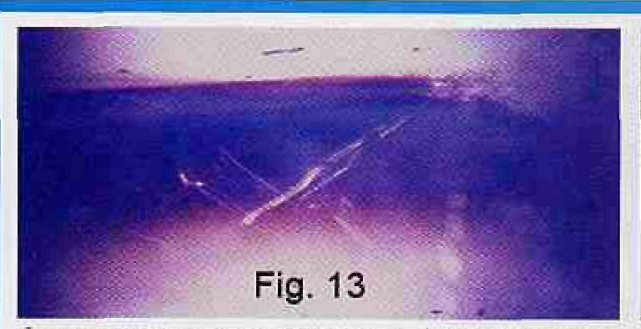

that as temperature increases, delamination increases. The increase of delamination with an increase in temperature from Company A's vials is shown in Figures 13, 14, and 15. A thinner bluish color "delamination" is seen at $25^{\circ} \mathrm{C}$ (Figure 13). There are more colors seen at $30^{\circ} \mathrm{C}$ (Figure 14) and a blast of color at $40^{\circ} \mathrm{C}$ (Figure 15). Company $\mathrm{C}^{\prime}$ s vials had similar results with increasing temperature.

The third group of vials examined was from Company B consisting of four vials which had been kept at $40^{\circ} \mathrm{C}, 30^{\circ} \mathrm{C}, 25^{\circ} \mathrm{C}, 4^{\circ} \mathrm{C}$ respectively for an eight week period. To recap, the four week period had pitting at every temperature except $4^{\circ} \mathrm{C}$. There was no delamination, but there
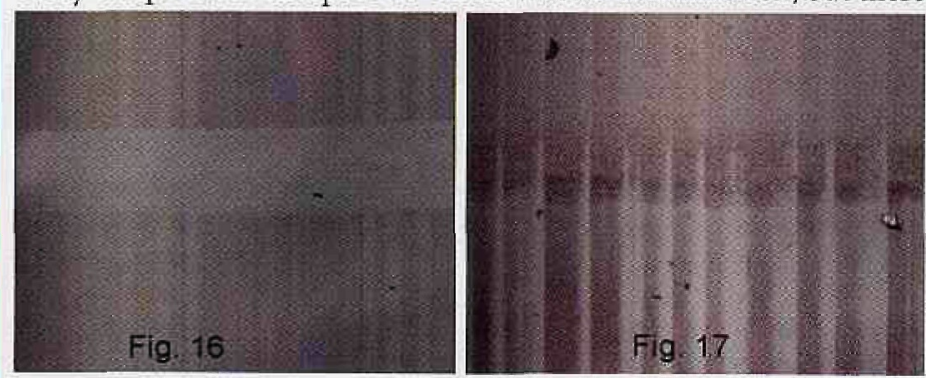

were striations with the discoloration in between. At the eight week time period pitting was seen at the base of all vials except at $25^{\circ} \mathrm{C}$, where no pitting was seen. The only temperature with pitting at the neck of the vial was at $40^{\circ} \mathrm{C}$. Delamination was seen only at $40^{\circ} \mathrm{C}$ and $30^{\prime \prime} \mathrm{C}$. Discoloration and striations were seen on every vial. There was no discoloration found on $25^{\circ} \mathrm{C}$, which corresponds to the four week period where there is some discoloration and faint striations. Results show again as temperature and now as time increases (from 4 weeks to 8 weeks), the more prevalent delamination becomes.

Figures 16 and 17 show the striations and discoloration from Company B's vials; the eight week period shows more developed striations and discoloration than the four week period. Figure 16 shows an area with a clear space between the striations; it is possible this area was common to where the fill-line would be. X-ray photoemission spectrography (XPS) was used to analyze the surface of several pieces of each company's vials to determine delamination. Using XPS, one obtains a surface analysis of the outermost 1 -

$5 \mathrm{~nm}$ of a solid sample. An atomic percentage was measured for carbon, oxygen, silicon, aluminum, sodium, calcium, magnesium, nitrogen, and other trace elements $(<0.5 \%)$ for each sample. Only vials of Company $A$ and $B$ were analyzed using this technique. The results show that many of these vials are delaminating.

XPS results are shown in Table 1. Sample 10 is a reference (clean) vial from Company B that was unexposed to the drug. Sample 5 is from a clean area of a vial from Company $B\left(4^{*} \mathrm{C} / 4\right.$ week) that had been exposed to the drug. Samples 1-6, and 9 are from Company B; samples 7 and 8 are from Company A.

The bottom shaded row in Table 1 is the reference vial (Sample 10). In comparing the other samples to sample 10 , results indicate that
Fig. 15

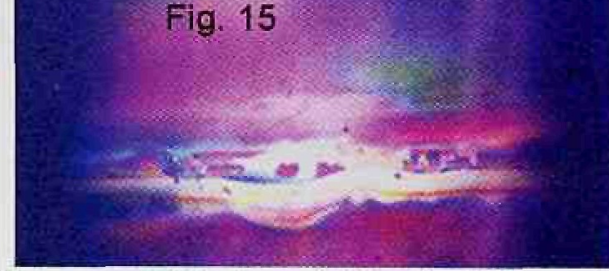

the atomic percent of the more soluble elements $(\mathrm{Na}, \mathrm{Ca}, \mathrm{Mg})$ associated with glasses were high from the norm, while silicon was low from the norm, which could be related to glass delamination exposing fresh glass. Another significant change is that carbon is going up and oxygen is going down, which is likely attributable to an organic residue:

- Samples 1 ( $30^{\circ} \mathrm{C} / 4$ week) and $2\left(40^{\circ} \mathrm{C} / 8\right.$ week) had the brown residue. This was difficult to explain, but since carbon and the more soluble elements go up, and oxygen and silicon go down, possible explanations are that this is residue from product or cleaning.

- Sample $6\left(25^{\circ} \mathrm{C} / 4\right.$ week $)$ has the striations; the more soluble elements are high, which suggests delamination exposing fresh glass. It is possible that the striations were present since manufacturing and that these etched away more with increasing time and temperature.

- The results from sample $9\left(55^{\circ} \mathrm{C}\right)$ suggest delamination.

- Samples 7 and $8\left(55^{\circ} \mathrm{C}\right)$ have the dark and pinkish residue that seems similar to delamination; their XPS results suggest delamination.

Can pitting be related to delamination? We have learned pitting occurs frequently and is common with delamination flakes. A vial not related to these studies, but of similar type, was sent out to a company that measures $3 \mathrm{D}$ surface texture. Their definition of surface texture measurement is derived from a measurement of the heights of the various image points. Pitting parameters and profiles were determined on the vial's base and center. The base area of the vial is shown in Figure 18. If the $\mathrm{X}$ and $\mathrm{Y}$ axes are visualized, they cross over certain pitting along the surface. The blue area is a larger pit that corresponds to $-100-200 \mathrm{~nm}$ on the colored scale and in the horizontal profile, it can be determined that the pit depth is $\sim 150 \mathrm{~nm}$. If the whole picture is looked at, the $3 \mathrm{D}$ image shows the blue areas spiking down from the surface. We can speculate that as these pits grow larger and/or appear in greater number, they can begin to form a flat surface resulting in the flaky appearance, which becomes glass delamination. Figure 19 shows measurements from the center of the provided vial; this seems to show

Table I. XPS Analysis Results on Glass Samples. Research Project MA03-397.

\begin{tabular}{|c|c|c|c|c|c|c|c|c|c|}
\hline Sample & 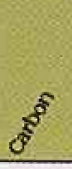 & $\hat{s}^{\delta}$ & 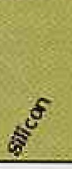 & Atomic & $s^{5}$ & $\frac{\delta^{5}}{8}$ & $\xi^{s}$ & $\hat{s}^{8}$ & $\begin{array}{l}\text { Other } \\
\text { Trace } \\
\text { (so.5\%o) }\end{array}$ \\
\hline Sample 1 & 20.0 & 55.1 & 20.6 & 1.2 & 1.9 & 0.3 & 0.2 & 0.4 & $\mathrm{Cl}$ \\
\hline Sample 2 & 25.1 & 51.1 & 13.7 & 5.1 & 1.0 & 1.9 & $<0.2$ & 1.6 & $\mathrm{Cl}, \mathrm{Ba}$ \\
\hline Sample 5 & 16.9 & 58.0 & 23.0 & 0.4 & 0.6 & $<0.2$ & $<0.2$ & 0.7 & $\mathrm{Cl}$ \\
\hline Sample 6 & 17.2 & 58.3 & 16.9 & 2.3 & 3.6 & 0.5 & 0.5 & 0.6 & $\mathrm{Cl}$ \\
\hline Sample 7 & 25.2 & 52.3 & 19.5 & 0.8 & 0.9 & $<0.2$ & 0.2 & 0.9 & $\mathrm{Cl}$ \\
\hline Sample 8 & 14.2 & 59.6 & 18.5 & 3.1 & 1.5 & 0.8 & 0.6 & 1.2 & $\mathrm{Cl}$ \\
\hline Sample 9 & 15.6 & 60.4 & 19.0 & 1.8 & 1.0 & 0.6 & 0.6 & 0.5 & $\mathrm{Cl}$ \\
\hline Sample 10 & 123 & 617 & 25.5 & $<0.2$ & $<0,2$ & 50.2 & 50.2 & $<0.2$ & c) \\
\hline
\end{tabular}




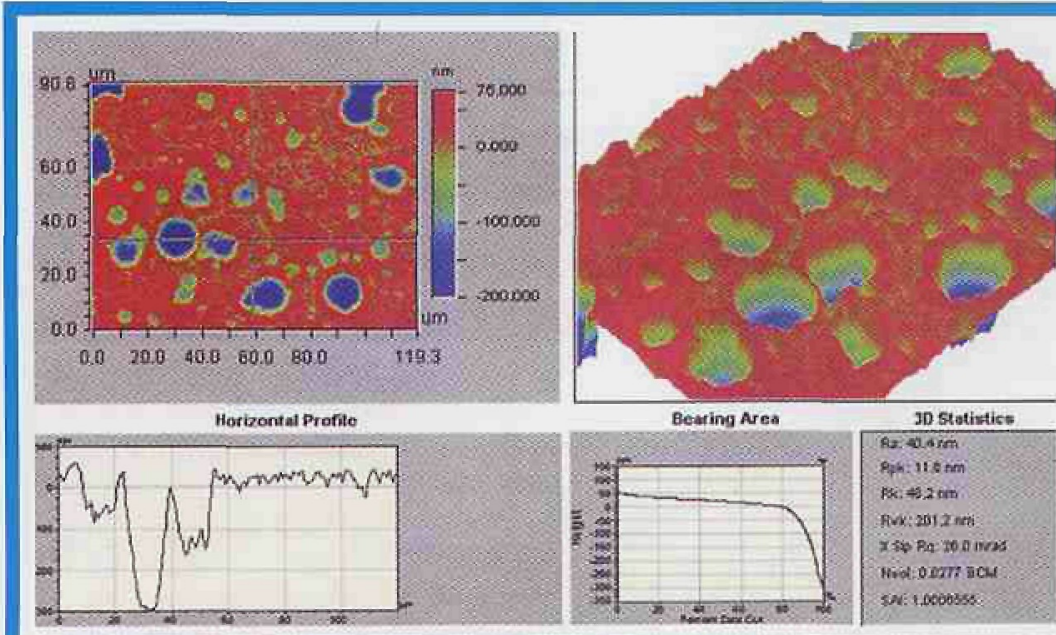

fine pitting. The data from these diagrams of surface texture measurements support a relation between pitting of a vial and glass delamination of a vial.

In summary, time and temperature studies provide good evidence that as time and temperature increase, delamination increases. There is a correlation between delamination and the type of drug the vial contains; and another correlation of delamination occurring in the area that is common to the fill-line. These correlations could have been more readily determined had we been supplied with vials contain the drug solution so that their fill lines could be accurately determined. In addition, the vials could then be examined, recorded, and the contents filtered under cleanroom conditions. XPS results show that when delamination occurs (exposing a new layer of glass); silicon goes down while the other soluble elements go up. There are also
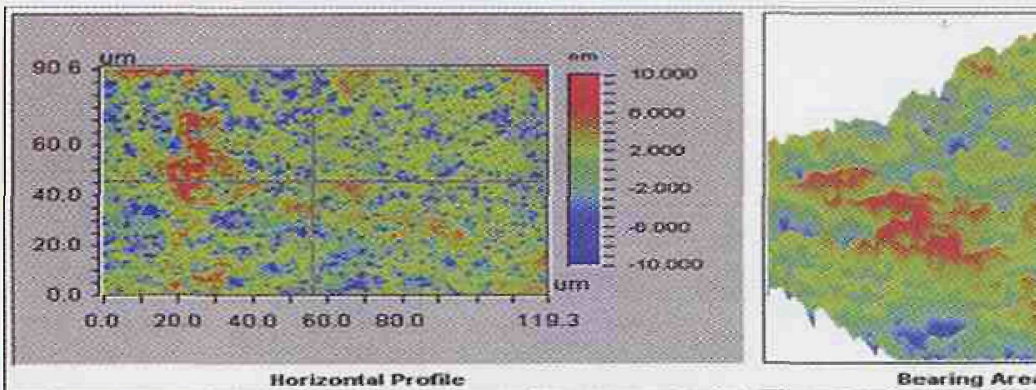

significant changes from a clean unexposed vial to an exposed vial. Pitting is still common, but not universally present, when delamination occurs and surface measurement analysis provides positive data.

A special thanks to $\mathrm{Mc}$ Crone Associate staff members, Scott Stoeffler for the SEM im-
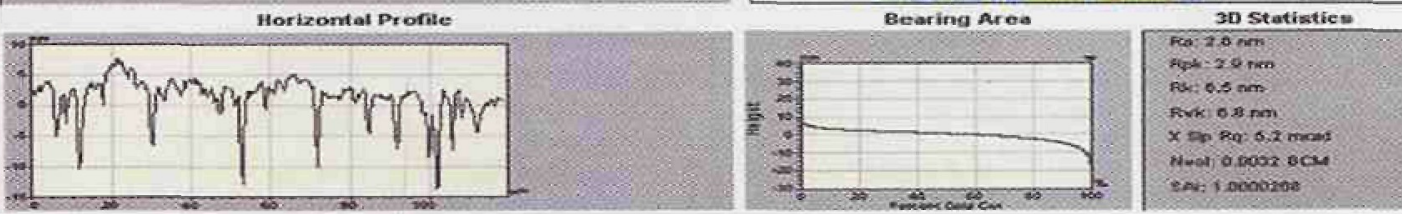
ages and IR data, Kent Rhodes for the XPS data, and Mark Bukantis for the surface texture measurement information.

\section{Microscopy Courses}

\section{MCCRONE COLLEGE OF MICROSCOPY}

McCrone Associates, Inc. offers training for microscopists

in their state-of-the-art Westmont, Illinois facility

\section{Scanning Electron Microscopy \\ November 8-12, 2004 \\ April 4-8, 2005 \\ October $17-21,2005$}

\section{Advanced FTIR Microscopy \\ September 13-17, 2004 \\ April 18-22, 2005}

\section{Particle Isolation, Manipulation \& Mounting \\ September $20-24,2004$ \\ May $9-13,2005$ \\ September 26-30, 2005}

\section{Particle Identification - White Powders January $10-14,2005$}

Online registration \& detailed course information available at www.mccrone.com

To register by telephone or e-mail contact the Course Registrar at 630-887-7100 or courses@mccrone.com

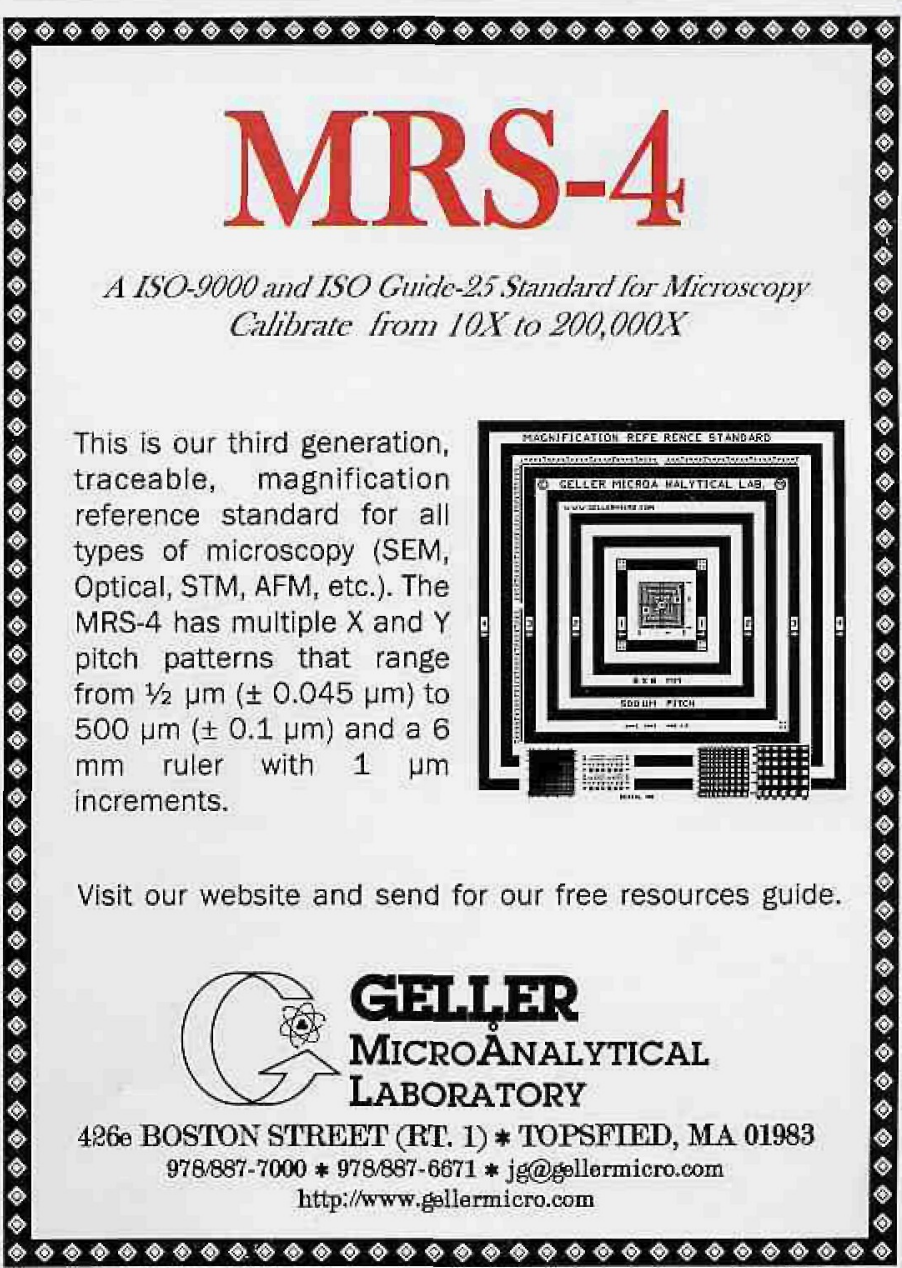

